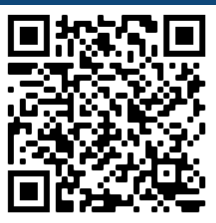

Keywords:

Stem taper

Localization

Variance function

Random parameters

Autocorrelation

Received 03/04/2020
Accepted 26/05/2020

Correspondence: ramazanozcelik@isparta.edu.tr
Ramazan Özçelik ${ }^{1 \mathrm{a}+}$, Onur Alkan ${ }^{1 \mathrm{~b}}$

\section{FITTING AND CALIBRATING A MIXED-EFFECTS SEGMENTED TAPER MODEL FOR BRUTIAN PINE}

ÖZÇELIK, R.; ALKAN, O. Fitting and calibrating a mixed-effects segmented taper model.

CERNE, v. 26, n. 4, p.464-473, 2020.

\section{HIGHLIGHTS}

A segmented mixed-effects taper model was developed in this study.

Different combinations of random parameters were tested.

To remove autocorrelation in residuals, a variance function and $\mathrm{CAR}(\mathrm{I})$ model used.

Use of upper stem diameter measurements provided more accurate predictions.

\section{ABSTRACT}

Taper models are one of several necessary tools in modern forest inventory, giving information on diameter at any point along the tree stem and this information can also be used to estimate stem volume. In this study, we used nonlinear mixed-effects (NLME) modeling approach to minimize existing statistical problems in constructing taper equations. A segmented taper model of Max and Burkhart (1976) was fitted using this approach to consider for within- and between-tree variation in brutian pine (Pinus brutia Ten.) stem taper. Based on evaluation statistics, the model including random-effects parameters $\beta$, $\beta_{3}$ and $\beta_{4}$ were found to be the best. Inclusion of random parameters were not completely eliminated heterogenous variance and autocorrelation in residuals. Incorporating variance function and a continuous autoregressive error structure (CAR(I)) to NLME Max and Burkhart model removed the heteroscedasticity and autocorrelation in residuals. Upper stem diameters were used to localized stem taper model to individual tree. For this, two different measurement scenarios were evaluated as one and two upper stem diameter measurements. Inclusion of random parameters were improved the predictive capability of taper model in particularly the middle and lower sections of stem based on upper stem diameter measurements. The calibration using upper stem diameter measurements can improve the tree-level accuracy of stem taper model is therefore recommended. 


\section{INTRODUCTION}

Brutian pine (Pinus brutia Ten.) is a one of the commercially tree species in the southern Turkey. This species has a significant share in the growing stock of this region, occupying an area of about 5.8 million ha. The corresponding standing volume of approximately 270.09 million $\mathrm{m}^{3}$ (GDF, 2006). Its wood has suitable properties for building and furniture materials such as door, window, ceiling and floor covering and in carving (Bozkurt and Göker 1996). Furthermore, brutian pine forest are important component of the Mediterranean forest as ecologically and supply environmental services and indirect benefits such as providing habitat to wildlife species and different plants, protecting in soil and water resources, and supporting agricultural productivity (Boydak 2004). Therefore, we need reliable information regarding growth and yield of the species to sustainable management of brutian pine forest, but this information is currently lacking in Turkey. Tree volume estimation is one of important tools of forest growth and yield modeling. Moreover, merchantable volume, total volume, total biomass, and total carbon are highly desired forest attributes for forest management decisions (Pancoast 2018). Total volume estimates are important for evaluating growth and yield, net primary production, stand dynamics, above ground biomass, and sustainable management of timber resources. Merchantable volume is used to determine economic value based on given dimensional specifications and market conditions. Above ground biomass estimations are used in carbon sequestration and climate change models and fuel production in place of traditional fossil fuel sources (Pancoast 2018).

The use of taper equations in predicting tree diameter, volume, and weight has recently become an increasingly popular trend (Klos et al. 2007; Sakıcı and Özdemir 2018). Taper models have an advantage over direct volume estimation in that they are flexible in predicting component biomass, in estimating upper stem diameters, and in merchantable volume estimation. To describe tree profile, different taper equations have been used over the years from simple forms to more complex forms. Three main approaches are applied: tree taper is described by simple taper model in the first approach (Kozak et al. 1969, Ormerod 1973, Biging 1984). The parts of a tree stem are defined by different geometric solid such as neiloid frustum, paraboloid frustum, cone for lower, middle, and upper portions of stem, respectively in the second approach. Segmented equations developed by Max and Burkhart (1976), Clark et al. (1991), and Fang et al. (2000) using this approach. In the third approach, assuming that tree form varies from one point to another along the bole (Kozak 1988; Sharma and Zhang 2004; Kozak 2004).

In most of these models, dbh and total height are used as independent variables. In addition, inclusion of additional predictors such as crown variables (Valenti and Cao 1 986, Leites and Robinson 2004, Li and Weiskittel 20 I0, Jiang and Liu 20II), upper stem diameters (Kozak 1998, Trincado and Burkhart 2006, Yang et al. 2009, Sabatia and Burkhart 20I5), stand characteristics (Sharma and Parton 2009, Jiang and Liu 20I I, Liu et al. 2020), management practices (Tasissa and Burkhart 1998), and climatic factors (Liu et al. 2020) has been considered in studies. However, in a number of studies, little improvement (Valenti and Cao 1986, Leites and Robinson 2004, Li and Weiskittel 2010, Sharma and Parton 2009, Jiang and Liu 20I I) or no improvement (Burkhart and Walton 1985, Muhairwe et al. 1994, Kozak 1998) was observed in model performance by including additional predictors as covariate. Improvements in performance of the model depend on the region, species, and precision of additional predictors measurements (Sharma and Parton 2009, Liu et al. 2020).

As stated by Arias-Rodil et al. (2017), among auxiliary variables, the most commonly evaluated variables have been upper-stem diameters (Trincado and Burkhart 2006, Cao and Wang 2015, Sabatia and Burkhart 2015, Arias-Rodil et al. 2015), gaining even more importance with the recent advances in instruments for measurements of upper stem diameters like laser technology. As also indicated by Burkhart and Tomè (20I2), inclusion of upper stem diameters to taper equation is one of the best approaches of accounting for within-tree variance in stem taper as auxiliary variable.

In generally, data that are collected for taper equations are most commonly hierarchical due to multiple diameter measurements along different data points on same tree. Therefore, data collected are not independent and are corelated. To address this problem, the mixedeffects models (NLME) have been used to model stem profile of tree because these models consider the correlation among multiple diameter observations on each individual stem. In these models, random effects which are specific to each subject individual, whereas fixed-effects parameters are common to population. Estimating the random effects from one or more upper-stem diameter measurements can be used for calibration of a mixedeffects taper equation (Cao and Wang 20II). Therefore, this modeling approach captures more variation among and within-trees. When mixed-effects modeling did not completely eliminate the error autocorrelation, a variance function or variance function plus an appropriate covariance structure can be corporate into model to account residual autocorrelation (Liu et al. 2020). 
The objectives of this study were to (I) develop a mixed-effects taper equation using model of Max and Burkhart (1976), (2) account for within-tree residual correlation and heterogeneous variance, and (3) calibrating taper equation based on upper stem diameters.

\section{MATERIAL AND METHODS}

Data

The data were collected from natural brutian pine from Bucak Forest Enterprise in Mediterranean Region of Turkey which represent the northern portion of brutian pine natural range. 280 destructively sampled brutian pine trees used in this study. Trees were sampled from a wide range of stand types, age and stand densities. The data were not included trees possessing broken tops, obvious cankers, and multiple stems. The felled trees were sectioned approximately I $\mathrm{m}$ intervals from stump to tip of tree. In addition to diameter at breast height $(d b h)$, total tree height (tht), and diameter outside barks were measured at the stump height and at the ends of each section. Two diameters were measured and then averaged for each section. The data were divided into a fitting sub-sample ( $85 \%$ of full data set) and evaluation sub-sample (I5\% of the observation) as randomly. Summary statistics of trees used in fitting and evaluation are depicted in Table I.

TABLE I Summary statistics for model fitting and validation data for Brutian pine.

\begin{tabular}{ccccc}
\hline Data & Mean & S.D. & Minimum & Maximum \\
\hline Fitting $(\mathrm{n}=238$ trees $)$ & & & & \\
\hline DBH $(\mathrm{cm})$ & 36.7 & 12.9 & 13.0 & 75.0 \\
Total height $(\mathrm{m})$ & 17.90 & 4.70 & 7.50 & 26.80 \\
Disk dob $(\mathrm{cm})$ & 24.2 & 13.6 & 1.0 & 79.0 \\
Disk height $(\mathrm{m})$ & 9.17 & $5.9 \mid$ & 0.30 & 26.30 \\
Volume $\left(\mathrm{m}^{3}\right)$ & 0.98 & 0.78 & 0.05 & 3.91 \\
\hline Evaluation $(\mathrm{n}=42$ trees $)$ & & & & \\
\hline DBH $(\mathrm{cm})$ & 36.6 & 13.7 & 14.0 & 68.0 \\
Total height $(\mathrm{m})$ & 17.50 & 5.30 & 7.50 & 25.50 \\
Disk dob $(\mathrm{cm})$ & 24.2 & 14.0 & 1.0 & 79.0 \\
Disk height $(\mathrm{m})$ & 9.35 & 6.11 & 0.30 & 25.30 \\
Volume $\left(\mathrm{m}^{3}\right)$ & 0.93 & 0.83 & 0.06 & 3.11 \\
\hline
\end{tabular}

The alteration of the relative diameter and relative height with the loess regression line is depicted in Figure I.

Stem taper modeling

Based on the previous studies (Cao et al. 1980; Coble and Hilpp 2006; Brooks et al. 2008; Sakıcı et al. 2008), taper model of Max and Burkhart (1976) indicated better results in predicting tree diameter and volume and therefore, this model was chosen for further analysis. In this study, we
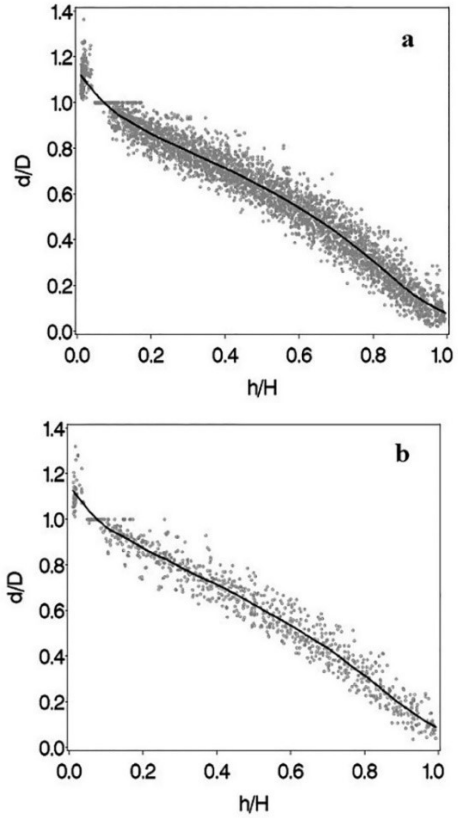

FIGURE I Plots of relative height versus relative diameter outside bark for Brutian pine.

adopted the two-stage model structure that presented by Davidian and Giltinan (1995) to define within-and betweenindividual variations. Accordance with this approach, a general expression for mixed-effect Max and Burkhart's taper model can be written for within-tree variation as Trincado and Burkhart (2006) pointed out (equation I and 2). Where for $i^{\text {th }}$ individual, $H_{i}=$ tree height $(\mathrm{m}), h_{i j}=$ height $(\mathrm{m})$ above the ground, $D_{i}=$ diameter outside bark $(\mathrm{cm})$ at breast height, $d_{i j}=$ diameter outside bark $(\mathrm{cm})$ at height $h_{i j}, \beta_{1 i}, \beta_{2 i}, \beta_{3 i}, \beta_{4 i}, \alpha_{1 i}, \alpha_{2 i}$ = parameters, $e_{i j}=$ error term with $E\left(e_{i j} \beta_{i}\right)$, where $\beta_{i}$ is the vector for parameters.

$y_{i j}=\beta_{1 i}\left(x_{i j}-1\right)+\beta_{2 i}\left(x_{i j}^{2}-1\right)+\beta_{3 i}\left(\alpha_{1 i}-x_{i j}\right)^{2} I_{1}+\beta_{4 i}\left(\alpha_{2 i}-x_{i j}\right)^{2} I_{2}+e_{i j}$

$I_{k}=\left\{\begin{array}{ll}1 & x \leq a_{k i} \\ 0 & x>a_{k i}\end{array} \quad k=1,2 y_{i j}=d_{i j}^{2} / D_{i}^{2}, x_{i j}=h_{i j} / H_{i}\right.$

Because the data structure for stem profiles represents hierarchical unbalanced repeated measurements made across space for an individual, the equation can be generalized into a vector form as, where, [4] and $\beta_{i}$ are assumed to follow multivariate normally distributed with and variance-covariance matrix $R_{i}\left(\beta_{i}, \xi\right)$. The vector $\xi$ represents a vector of unknown parameters $\left[\sigma, \theta^{\prime}, p^{\prime}\right]^{\top}$ common for all individuals. As suggested by Trincado and Burkhart (2006), if needed, the variancecovariance matrix can be specified in general form to account for within-tree variance and autocorrelation among observations [5]. Where $G_{i}^{1 / 2}(\beta \mathrm{i}, \theta)$ and $\Gamma_{i}(p)$ are an $\left(n_{i} \times n_{i}\right)$ diagonal matrix that explaining the variance of within-tree heteroscedasticity and defines the correlation pattern within the observations of the $i^{\text {th }}$ tree, respectively. 


$$
\begin{aligned}
& y_{i}=\beta_{1 i}\left(x_{i}-1\right)+\beta_{2 i}\left(x_{i}^{2}-1\right)+\beta_{3 i}\left(\alpha_{1 i}-x_{i}\right)^{2} L_{1}+\beta_{4 i}\left(\alpha_{2 i}-x_{i}\right)^{2} I_{2}+\varepsilon_{i} \\
& y_{\mathrm{i}}=\left[y_{i 1}, y_{i 2}, \ldots, y_{i n_{i}}\right]^{T}, x_{\mathrm{i}}=\left[x_{i 1}, x_{i 2}, x_{i 3}, \ldots, x_{i n_{i}}\right]^{T}, \varepsilon_{\mathrm{i}}=\left[\varepsilon_{i 1}, \varepsilon_{i 2}, \ldots, \varepsilon_{i n_{i}}\right]^{T}[4] \\
& R_{\mathrm{i}}\left(\beta_{i}, \zeta\right)=\sigma^{2} G_{\mathrm{i}}^{1 / 2}\left(\beta_{i}, \theta\right) \Gamma_{i}(\rho) G_{i}^{1 / 2}\left(\beta_{i}, \theta\right)
\end{aligned}
$$

The previous studies have showed that even after the inclusion of random parameters into a model may not be able to eliminate of error autocorrelation completely. Therefore, different variance functions are evaluated to correct within- and between-tree heterogeneous error variance in this study. As suggested by Trincado and Burkhart (2006), for successive analysis and testing for inclusion in the model, two possible variance functions 6 and 7 were selected.

$$
\begin{aligned}
& g\left(\theta, x_{i j}\right)=\exp \left(\theta_{1} x_{i j}\right), e_{i j} \sim N\left(0, \exp \left(\theta_{1} x_{i j}\right)\right) \\
& g\left(\theta, x_{i j}\right)=D_{i}^{\theta_{\mathrm{o}}} \exp \left(\theta_{1} x_{i j}\right), e_{i j} \sim N\left(0, D_{i}^{\theta_{\mathrm{o}}} \exp \left(\theta_{1} x_{i j}\right)\right)
\end{aligned}
$$

The variance function (Eq.(6 and 7)) assumes heterogeneous within-tree variance as function of relative height. Contrarily, the variance function (Eq. $(8,9))$ models both heterogeneous within- and between-tree variance as function of relative height and dbh similar to approach of Trincado and Burkhart (2006). After selecting the most appropriate variance function, $\operatorname{CAR}(I)$ was incorporated into the model. The statistical significance of including a variance function and autocorrelation structure was evaluated through likelihood ratio tests (LRT) in the case of nested models (Pinheiro and Bates, 2000).

In the case of between-tree variation, in this modeling approach, the parameter vector $\beta_{i}$ accounts for between-individual variation. This variation varies from tree to tree. Therefore, the vector parameter $\beta$ can be expanded as, where: $\beta=$ vector of fixed population parameters of size $(p \times 1), b_{i}=$ vector of random-effects and of size $(p \times I), p=$ number of fixed-effects parameters, $q=$ number of random-effects parameters, $D=$ the random parameter's variancecovariance matrix. Furthermore, $A_{i}$ and $B_{i}$ are the fixed and random effects design matrix.

$\beta_{i}=A_{i} \beta+B_{i} b_{i}, b_{i} \sim N(0, D)$

To find the best random parameters combination, all different combinations of parameters $\left(\beta_{1}, \beta_{2}, \beta_{3}\right.$ and $\left.\beta_{4}\right)$ were evaluated using methodology applied by Trincado and Burkhart (2006). Three candidate models with two $\left(\beta_{\text {- }}\right.$ $\beta_{2}$ and $\left.\beta_{3}-\beta_{4}\right)$ and four $\left(\beta_{1}-\beta_{2}-\beta_{3}-\beta_{4}\right)$ parameters failed to converge. Therefore, totally twelve candidate models including mixed-effects and a model including only fixedeffects were fitted to stem taper data. Parameters estimates and subsequent analysis of the residual variance-covariance matrix were performed using the SAS macro NLINMIX (SAS Institute, Inc. 20II). The variance components were estimated with maximum likelihood (ML). The withinindividual residuals were presumed to have constant variance and uncorrelated errors for all mixed-effects models at this point. After the best model was identified, additional analyses were performed to detect and model the effects of variance heterogeneity and autocorrelation in the residuals. The fit evaluation criteria were a maximum likelihood estimate (ML) of $\sigma^{2}$ expressed as $\hat{\sigma}^{2}$ Akaike's Information Criterion (AIC; Akaike 1974), and twice the negative log-likelihood (-2 $\ln (L))$.

Tree-level random parameters $b_{k}$ were computed using by use of an approximate Bayes estimator. The expression is as follows, where: $\widehat{R}_{k}$ is variancecovariance matrix for residuals and is matrix of variancecovariance for the random-effects. Predicting the vector of random parameters implies estimations $Z_{k}$ and $e_{k}$, which is computed as, 10 and II respectively.

$$
\begin{aligned}
& \hat{b}_{k} \cong \widehat{D} \hat{Z}_{k}^{\prime}\left[\hat{Z}_{k} \widehat{D} \hat{Z}_{k}^{\prime}+\hat{R}_{k}\right]^{-1} \hat{e}_{k} \\
& \hat{Z}_{k}=\left.\frac{\partial f\left(A_{k} \beta, x_{k}\right)}{\partial \beta_{k}^{T}}\right|_{\beta_{k}=\hat{\beta}_{k}} \cdot B_{k} \\
& \hat{e}_{k}=y_{k}-f\left(A_{k} \beta, x_{k}\right)
\end{aligned}
$$

Model evaluation

For this aim, the evaluation data set was divided into 10 relative stem height classes and then the differences between measured and predicted stem diameter outside bark were computed for observations for each relative stem height. The mean bias and root mean square error (RMSE) within each class were calculated. As indicated by Xu (2 I02), RMSE gives an overall measures of model accuracy since it combines the mean bias and variation of the biases. Therefore, RMSE was used in this study as a primary criterion for model evaluation. To determine effects of position and number of upper stem diameter selected, two separate measurement scenarios were used and compared when choosing the upper stem diameter for calibration: (i) only one upper stem diameter at absolute stem heights of $2.3 \mathrm{~m}, 3.3 \mathrm{~m}, 4.3 \mathrm{~m}, 5.3 \mathrm{~m}$, and $6.3 \mathrm{~m}$; and (ii) two upper stem diameters measured at 3.3 and $6.3 \mathrm{~m}$. Because it is more practical to obtain in forestry applications, absolute height was used.

\section{RESULTS}

\section{Mixed-effects segmented taper equation}

Fit statistics for a model containing only fixed effects and twelve models containing one, two or three random-effects are given in Table 2 . 
TABLE 2 Selection criteria values for taper model fitted with various combinations of mixed parameters.

\begin{tabular}{|c|c|c|c|c|}
\hline $\begin{array}{l}\text { Random } \\
\text { Parameters }\end{array}$ & $\begin{array}{l}\text { Estimated } \\
\text { Parameters }\end{array}$ & $\sigma^{2}$ & $\begin{array}{c}-2 \mathrm{LL} \\
\text { (smaller is } \\
\text { better) }\end{array}$ & $\begin{array}{c}\text { AIC } \\
\text { (smaller is } \\
\text { better) }\end{array}$ \\
\hline None & 7 & 0.00549 & -9422.5 & -9420.5 \\
\hline$\beta_{1}$ & 9 & 0.00282 & $-1 \mid 400.4$ & -11396.4 \\
\hline$\beta_{2}$ & 9 & 0.00265 & -11613.7 & -11609.7 \\
\hline$\beta_{3}$ & 9 & 0.00361 & -10540.5 & -10536.5 \\
\hline$\beta_{4}$ & 9 & 0.00449 & -9849.7 & -9845.7 \\
\hline$\beta_{1}, \beta_{3}$ & 10 & 0.00170 & $-|2454|$. & -12448.1 \\
\hline$\beta_{1}, \beta_{4}$ & 10 & 0.00157 & -12913.1 & -12907.1 \\
\hline$\beta_{2}, \beta_{3}$ & 10 & 0.00171 & -12585.2 & -12579.2 \\
\hline$\beta_{2}, \beta_{4}$ & 10 & 0.00148 & $-13 \mid 58.0$ & -13152.0 \\
\hline$\beta_{1}, \beta_{2}, \beta_{3}$ & 13 & 0.00147 & -13023.7 & -13009.7 \\
\hline$\beta_{1}, \beta_{2}, \beta_{4}$ & 13 & 0.00090 & -14435.2 & -14421.2 \\
\hline$\beta_{1}, \beta_{3}, \beta_{4}$ & 13 & 0.00088 & $-|4505|$. & $-|449| . \mid$ \\
\hline$\beta_{2}, \beta_{3}, \beta_{4}$ & 13 & 0.00089 & $-1447 \mid .9$ & -14457.9 \\
\hline
\end{tabular}

The significant differences were found between models containing various combinations of random-effects parameters in comparison to the model that considered only fixed-effect parameters (Table 2). In all cases those models including mixed-effects fit the data better than a model including only fixed parameter. Based on evaluation criteria as AIC and $-2 L L$, the mixed-effects combination of $\beta_{1}, \beta_{3}$ and $\beta_{4}$ produced the lowest AIC and $-2 L L$, resulting in the model including three estimated random-effects parameters was the best. The final NLME model was, where $u_{1 i}, u_{2 i}$ and $u_{3 i}$ are the random-effects parameters estimated by the $i^{\text {th }}$ tree.

The parameter estimations for Eq.(I2) (Model 2) are given in Table 4.

$y_{i j}=\left(\beta_{1}+u_{1 i}\right)\left(x_{i j}-1\right)+\beta_{2}\left(x_{i j}^{2}-1\right)+\left(\beta_{3}+u_{i i}\left(\alpha_{1 i}-x_{i j}\right)^{2} I_{1}+\left(\beta_{4}+u_{3 i}\right)\left(\alpha_{2 i}-x_{i j}\right)^{2} l_{2}+e_{i j}\right.$

Distribution of studentized residuals displayed that predictions from the fixed-effects equation (Model I-Figure 2a) had a more heterogenous residual variance than selected mixed-effects model (Model 2-Figure 2b). However, even with the inclusion of random effects, a degree of heterogeneity was observed.

The use of variance functions was considered to be significant for both functions tested when the model was again fit assuming the within-trees residual variance is heterogeneous (Table 3). Thus, even after the inclusion of random effects, variance heterogeneity was still present and needs to be accounted for in the model. The best fit was obtained with taper model with variance function (Model 3), which included a variance function (eq.(5)) that simultaneously accounted for both within- and between-tree residual variability. The term $x_{i j}$ (relative stem height) and $D_{i}$
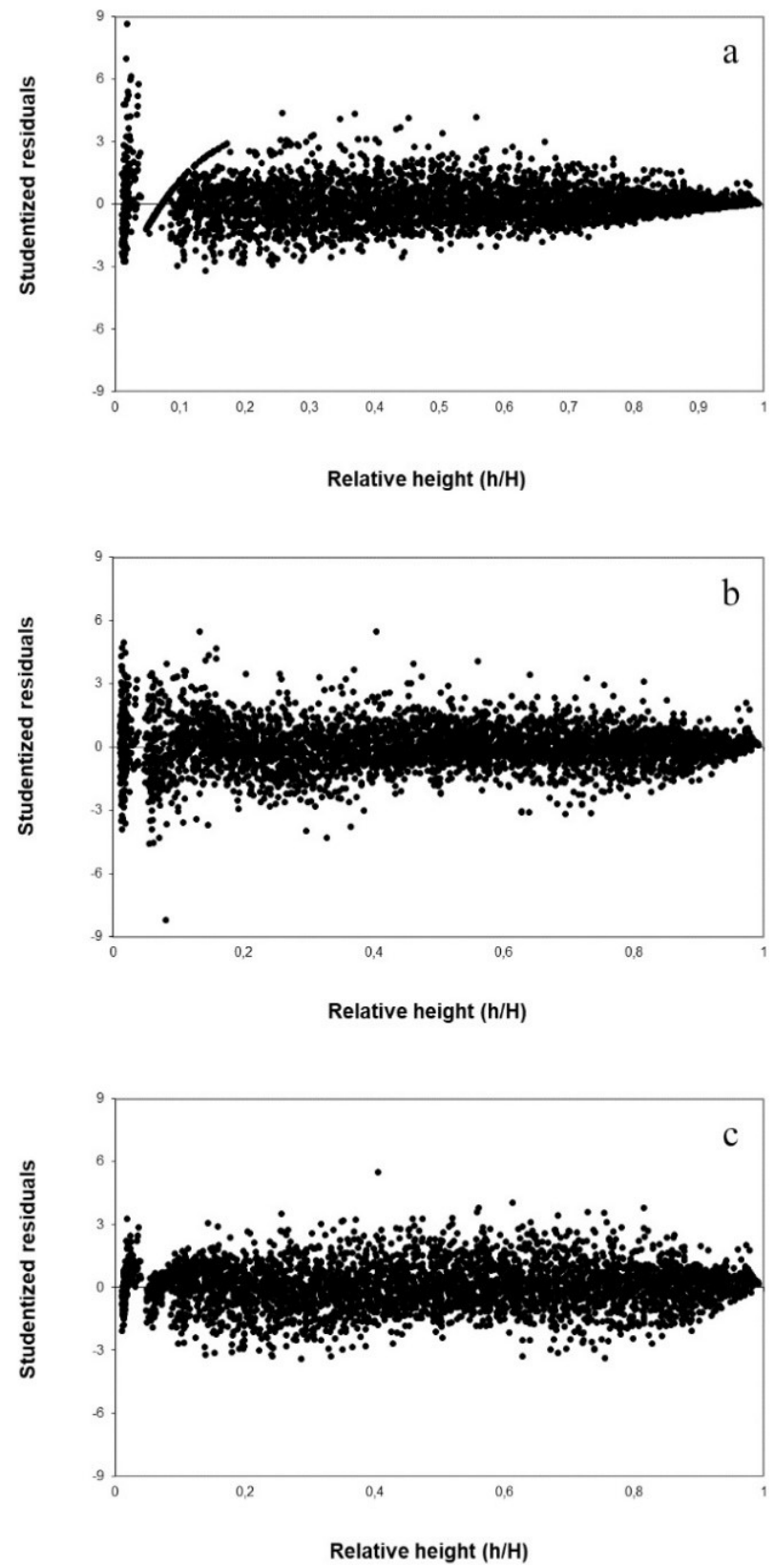

FIGURE 2 Studentized residuals for the (a) fixed-effects model (Model I), (b) mixed-effects model with $\beta_{1}, \beta_{3}$, and $\beta_{4}$ having random-effects assuming homogeneous residuals variance (Model 2), and (c) mixed-effects model with inclusion of a residual variance function (Model 3 ).

TABLE 3 Fit statistics and LRT for models with different variance functions.

\begin{tabular}{ccccccc}
\hline Alternatives & $\begin{array}{c}\text { Variance } \\
\text { function } \\
g\left(\theta, x_{i j}\right)\end{array}$ & $\begin{array}{c}\text { Parameters } \\
(\mathrm{k})\end{array}$ & AIC & $\operatorname{Ln}(L)$ & LRT & $p$-value \\
\hline I & none $\mathrm{a}^{\mathrm{a}}$ & 13 & -14491.1 & 7252.55 & & \\
2 & $\exp \left(\theta_{1} x_{i j}\right)$ & 14 & -15095 & 7561.50 & 617.90 & $<0.001$ \\
3 & $D_{i}^{\theta_{0} \exp \left(\theta_{1} x_{i j}\right)}$ & 15 & -15409 & 7719.50 & 933.90 & $<0.001$ \\
\hline
\end{tabular}

ahomogeneous error variance i.e. $\operatorname{var}\left(e_{i j}\right)=\sigma^{2}$. 
TABLE 4 Parameter estimates for fixed-effects parameters (Model I), fixed- and random-effects parameters (Model 2), fixed- and random effects parameters with variance function (Model 3), and fixed- and random effects parameters with variance function and $\operatorname{CAR}(\mathrm{I})$ (Model 4).

\begin{tabular}{|c|c|c|c|c|c|c|c|c|}
\hline \multirow{2}{*}{ Parameters } & \multicolumn{2}{|c|}{ Model I } & \multicolumn{2}{|c|}{ Model 2} & \multicolumn{2}{|c|}{ Model 3} & \multicolumn{2}{|c|}{ Model 4} \\
\hline & Estimate & SE & Estimate & SE & Estimate & SE & Estimate & SE \\
\hline$\beta_{1}$ & -3.5942 & 0.6184 & $-3.575 I$ & 0.2335 & -3.4912 & 0.0898 & -3.5096 & 0.1674 \\
\hline$\beta_{2}$ & 1.7268 & 0.3427 & $\mathrm{I} .7055$ & 0.1295 & 1.6619 & 0.0496 & 1.6798 & 0.0934 \\
\hline$\beta_{3}$ & -1.3997 & 0.3282 & -1.4002 & 0.1256 & -1.4435 & 0.0548 & -1.3490 & 0.0958 \\
\hline$\beta_{4}$ & 12.5313 & 1.2545 & II .4040 & 0.7289 & 7.1524 & 0.6040 & 14.3743 & 1.0154 \\
\hline$\alpha_{1}$ & 0.7768 & 0.0376 & $0.77 \mid 4$ & 0.0148 & 0.7522 & 0.0073 & 0.7701 & 0.0119 \\
\hline$a_{2}$ & 0.1518 & 0.0075 & 0.1583 & 0.0032 & 0.1997 & 0.0063 & 0.1391 & 0.0039 \\
\hline \multicolumn{9}{|c|}{ Variance components } \\
\hline$\sigma^{2}$ & 0.00549 & & 0.00088 & & 0.2454 & & 0.5046 & \\
\hline $\operatorname{Var}\left(b_{1}\right)$ & & & 0.03639 & & 0.0334 & & 0.0225 & \\
\hline $\operatorname{Var}\left(b_{3}\right)$ & & & 0.1219 & & 0.1636 & & 0.0697 & \\
\hline $\operatorname{Var}\left(b_{4}\right)$ & & & 72.3724 & & 29.4264 & & 91.6160 & \\
\hline $\operatorname{Cov}\left(b_{1}, b_{3}\right)$ & & & 0.05548 & & 0.05761 & & 0.0374 & \\
\hline $\operatorname{Cov}\left(b_{1}, b_{4}\right)$ & & & 0.03753 & & -0.06534 & & -0.1620 & \\
\hline $\operatorname{Cov}\left(b_{3}, b_{4}\right)$ & & & -0.8826 & & -1.1836 & & -0.8506 & \\
\hline \multicolumn{9}{|c|}{ Variance structure } \\
\hline$\theta_{0}$ & & & & & -1.2080 & & -1.2080 & \\
\hline$\theta_{1}$ & & & & & -2.8987 & & -2.8987 & \\
\hline \multicolumn{9}{|c|}{ Covariance structure } \\
\hline$\rho$ & & & & & None & & 0.7454 & \\
\hline \multicolumn{9}{|c|}{ Goodness-of-fit } \\
\hline$-2 \mathrm{LL}$ & -9422.5 & & $-|4505|$. & & -15439 & & -16699.5 & \\
\hline $\mathrm{AIC}$ & -9420.5 & & - |449|.| & & -15409 & & -16683.5 & \\
\hline
\end{tabular}

(tree size) accounted for within-tree variability and betweentree variability, respectively. Parameter estimates of taper model with variance function are depicted in Table 4 for Model 3. After inclusion of the variance function, the new model (Model 3-Figure 2c) produced more homogeneous residual along the relative stem heights. For evaluated variance functions, fit statistics based on $A / C$ and $\operatorname{Ln}(L)$ and likelihood ratio test (LRT) are given in Table 3 .

As indicated by Trincado and Burkhart (2006), according to formula (3), the diagonal matrix that describes the within-individual variance can be expresses as:

$G_{i}=\left[\begin{array}{ccc}D_{i}^{\theta_{0}} \exp \left(\theta_{1} x_{i 1}\right) & 0 & 0 \\ 0 & D_{i}^{\theta_{0}} \exp \left(\theta_{1} x_{i 2}\right) & 0 \\ 0 & 0 & D_{i}^{\theta_{0}} \exp \left(\theta_{1} x_{i 3}\right)\end{array}\right]$

As stated by many researcher (Yang et al. 2009; Cao and Wang 20I5; Liu et al. 2020), correlated errors are possible, when repeated measurements are used, even after including random-effects parameters. Consequently, a more complete model is required to test for residual dependence. Model 3 was fitted with $\operatorname{CAR}(I)$ to eliminate autocorrelation among residuals from same individual, which is theoretically the most sound and practical structure for application (Dièguez-Aranda et al., 2006). The fitting carried out with NLINMIX used the variance function of model 3 as a weighing factor for the residual variance of a model containing an autocorrelated error structure. The implication of an autocorrelation structure corrected the fit of the model (Model 4) as observed when comparing the AIC and $-2 \mathrm{LL}$ values (Table 4). The significance of including an autocorrelation error structure was tested applying Likelihood ratio test (LRT). LRT showed significant improvements of model 4 (using LRT $=1260.5$ was significant at $\alpha<0.001$ ( $x_{1,0.001}=$ 10.828), where $\sigma^{2}=0.5046, \theta=[-1,2080-2.8987]$ $T$ and $\rho=0.7454$ (Table 4). This structure presumes that the errors are correlated and that the within- and between-tree residual variances are heterogeneous.

$\Gamma_{i}=\left[\begin{array}{ccc}1 & \rho^{d_{12}} & \rho^{d_{13}} \\ \rho^{d_{21}} & 1 & \rho^{d_{23}} \\ \rho^{d_{32}} & \rho^{d_{32}} & 1\end{array}\right]$

$R_{i}=\sigma^{2}\left[\begin{array}{ccc}D_{i}^{\theta_{0}} \exp \left(\theta_{1} x_{i 1}\right) & \rho^{d_{12}} & \rho^{d_{13}} \\ \rho^{d_{21}} & D_{i}^{\theta_{0}} \exp \left(\theta_{1} x_{i 2}\right) & \rho^{d_{23}} \\ \rho^{d_{18}} & \rho^{d_{25}} & D_{i}^{\theta_{0}} \exp \left(\theta_{1} x_{i 3}\right)\end{array}\right]$

For between-tree variation, the parameter vector $\beta_{i}$ for the $i^{\text {th }}$ individual can be expressed as 17 , where $\beta$ is a $\left[\beta_{1}, \beta_{2}, \beta_{3}, \beta_{4}, \alpha_{1}, \alpha_{2}\right]^{\top}$ and $b_{i}$ is a $y_{i}=\left[b_{1 i}, b_{3 i}, b_{4 i}\right]^{\top}$ vectors of fixed- and random-effects, respectively. $A_{i}=I_{6}$ is a $(6 \mathrm{x}$ 6 ) identity matrix for the fixed effects, and $B_{i}$ is a $y_{i}=[100$, $000,010,001,000,000]^{T}$ design matrix for random effects. $\beta_{i}=A_{i} \beta+B_{i} b_{i}=I_{6}\left[\begin{array}{c}\left(\beta_{1}+b_{1 i}\right) \\ \beta_{2} \\ \left(\beta_{3}+b_{3 i}\right) \\ \left(\beta_{4}+b_{4 i}\right) \\ \alpha_{1} \\ \alpha_{2}\end{array}\right]=\left[\begin{array}{c}\beta_{1 i} \\ \beta_{2 i} \\ \beta_{3 i} \\ \beta_{4 i} \\ \alpha_{1 i} \\ \alpha_{2 i}\end{array}\right] \quad b_{i} \sim N(0, D)$ 
$D=\left[\begin{array}{ccc}\operatorname{Var}\left(b_{1}\right) & \operatorname{Cov}\left(b_{1}, b_{3}\right) & \operatorname{Cov}\left(b_{1}, b_{4}\right) \\ & \operatorname{Var}\left(b_{3}\right) & \operatorname{Cov}\left(b_{3}, b_{4}\right) \\ & & \operatorname{Var}\left(b_{4}\right)\end{array}\right]=\left[\begin{array}{rrr}0.02236 & 0.03712 & -0.1641 \\ 0.03712 & 0.06931 & -0.8552 \\ -0.1641 & -0.85520 & 91.1981\end{array}\right]$

Visually, the mixed-effects equation better fits the stem profile than the equation including only fixedeffects parameters (Figure 3).

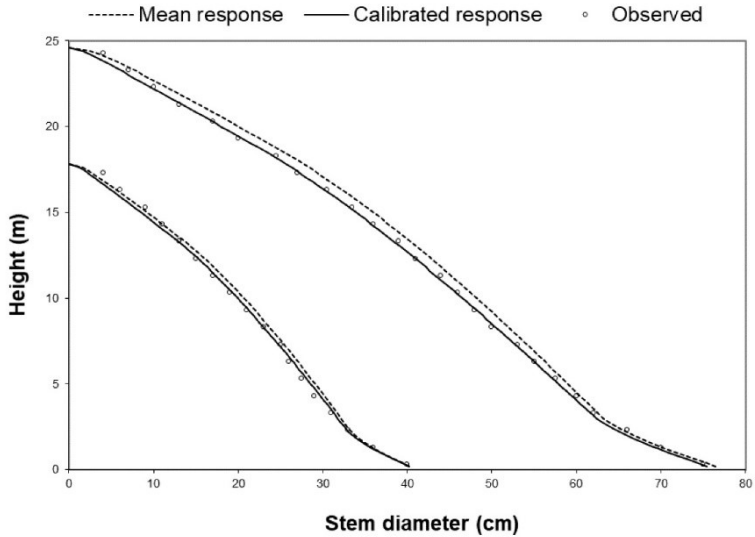

FIGURE 3 Stem profile curves using NLME approach with non-prior (mean response) and two prior stem diameters (calibrated response) at $3.3 \mathrm{~m}$ and $6.3 \mathrm{~m}$ for sample trees $(\mathrm{dbh}=68 \mathrm{~cm}$ and $36 \mathrm{~cm}$; $\mathrm{h}=24.6 \mathrm{~m}$ and $17.8 \mathrm{~m})$.

\section{Evaluation of upper stem diameter predictions}

Measures of bias and RMSE for the both responses (mean and calibrated) using stem diameter measurements for different relative stem heights are presented in Table 5 . The model with the smallest values of mean bias by each relative stem heights was considered to be the best. When considering all the observations the calibrated response showed the lowest bias. In the lower section of the bole, the smallest values of bias are obtained for the calibrated response which considers the measurement of one upper stem diameter. In the lower and middle portions of the bole (below $80 \%$ of total height) the smallest values of RMSE are obtained for the calibrated response using two upper stem diameter measurements except for $10-20 \%$ of total height. Contrarily, the mean response presented the lowest RMSE in the upper section of the bole at relative heights between $80-100 \%$.

These results showed that two stem diameter measurements are required to accurately calibrate the taper equation for brutian pine. However, a graphical analysis of these errors indicated that predicting capability of the model was not greatly diminished when only one stem measurement at $6.3 \mathrm{~m}$ was used (Figure 4).

A graphical analysis of the RMSE indicates that accuracy was not greatly diminished over a relative stem height of 0.4 when only one stem measurement at $6.3 \mathrm{~m}$ is performed (Figure 4). These evaluations demonstrate that accuracy of the tree taper model can improve with

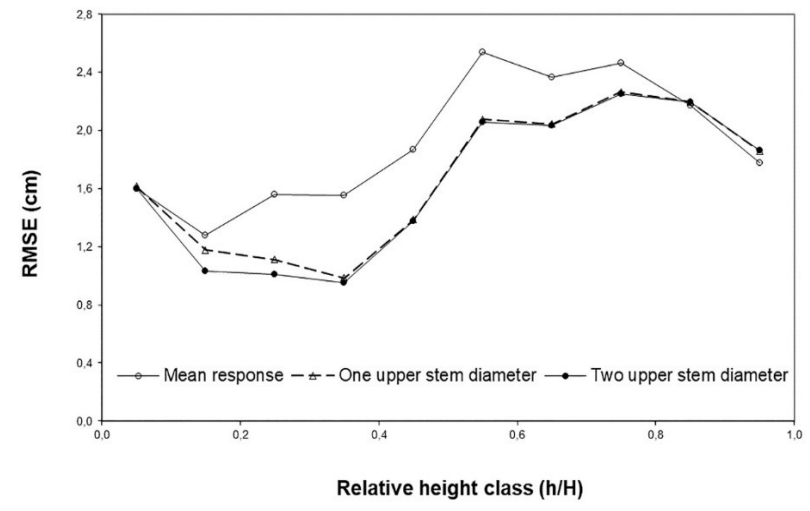

FIGURE 4 RMSE for the mean and calibrated responses predictions using one (at $6.3 \mathrm{~m}$ ) and two upper stem diameters $(3.3 \mathrm{~m}$ and $6.3 \mathrm{~m})$ by relative height classes.

calibration, particularly in the lower part of the stem, where most of the volume and value is concentrated.

\section{DISCUSSION}

A segmented taper model was developed for natural brutian pine stands using nonlinear mixed-effects modeling approach. The inclusion of random-effects provided better model fitting in comparison to a fixedeffects model. Based on fit statistics, a model containing random-effects for the three parameters $\left(\beta_{1}, \beta_{3}\right.$ and $\left.\beta_{4}\right)$ was found to be best.

In this work, the effects of residual variance heterogeneity and residual autocorrelation were incorporated to model the variance-covariance matrix. In addition, as upper stem diameter(s) were available an approximate Bayes estimator was obtained to estimate the vector of random effects for a new tree. Heteroscedasticity and residual autocorrelation need to be accounted for in taper modeling process. Based on results of some studies (Leites and Robinson 2004, Sharma and Parton 2009), use of the mixed-effects models including both fixed- and random-effects parameters are enough to remove heteroscedasticity and autocorrelation from residuals of the model. However, some studies have depicted that the autocorrelation can be diminished but cannot be completely eliminated by the use of randomeffects parameters (Trincado and Burkhart 2006, Yang et al. 2009, Gòmez-Garcia et al. 2013, Arias-Rodil et al. 2015). The incorporation of random-effects parameters was not completely eliminated the error autocorrelation in our study. Therefore, to eliminate autocorrelation and heteroscedasticity in residuals, incorporation of variance function and $C A R(I)$ model should be add to mixed-effects taper model. Based on the LTR results, including a variance function and $\operatorname{CAR}(\mathrm{I})$ autoregressive 
TABLE 5 Bias and RMSE for bole diameter predictions for the mean and calibrated responses by relative height classes.

\begin{tabular}{|c|c|c|c|c|c|c|c|c|c|c|c|c|c|c|c|}
\hline \multirow[b]{2}{*}{$\mathrm{RH}$} & \multicolumn{8}{|c|}{ Bias } & \multicolumn{7}{|c|}{ RMSE } \\
\hline & $\mathbf{n}$ & $\begin{array}{c}\text { Mean } \\
\text { response }\end{array}$ & $2.3 \mathrm{~m}$ & $3.3 \mathrm{~m}$ & $4.3 \mathrm{~m}$ & $5.3 \mathrm{~m}$ & $6.3 \mathrm{~m}$ & $\begin{array}{c}3.3 \mathrm{~m} \text { and } \\
6.3 \mathrm{~m}\end{array}$ & $\begin{array}{c}\text { Mean } \\
\text { response }\end{array}$ & $2.3 \mathrm{~m}$ & $3.3 \mathrm{~m}$ & $4.3 \mathrm{~m}$ & $5.3 \mathrm{~m}$ & $6.3 \mathrm{~m}$ & $\begin{array}{c}3.3 \mathrm{~m} \text { anc } \\
6.3 \mathrm{~m}\end{array}$ \\
\hline $0.0-0.1$ & 82 & 0.1459 & 0.1479 & 1647 & 0.1656 & 0.1242 & 0.1124 & 0.0752 & 996 & 1.6100 & 1.6143 & 1.6132 & 1.6162 & 1.6 & 1.5963 \\
\hline $0.1-0.2$ & 74 & -0.1882 & -0.1104 & -0.1318 & -0.2306 & -0.3417 & $-0.374 I$ & -0.2840 & 1.2813 & 1.0004 & 34 & 0.9634 & 1.0646 & I.1757 & 1.0300 \\
\hline $0.2-0.3$ & 74 & 0.2417 & 0.3416 & 0.3325 & 0.2203 & 0.0716 & 0.0304 & 0.1037 & 1.5613 & 1.3855 & $1.264 \mid$ & 1.1033 & 1.0672 & 1.1113 & 1.0090 \\
\hline $0.3-0.4$ & 69 & 0.2706 & 0. & 79 & 0.2626 & 661 & 73 & 1 & 30 & 1.5225 & 452 & 1.3616 & 1.1413 & 0.9847 & 539 \\
\hline $0.4-0.5$ & 72 & 0.4367 & 0.5463 & 0.5252 & 0.4239 & 0.1963 & 0.1083 & 0.1443 & 1.8658 & 2.0008 & 1.9053 & 1.9310 & 1.5958 & $1.386 \mathrm{I}$ & 1.3778 \\
\hline $0.5-0.6$ & 77 & 0.6609 & 0.7554 & 0.7536 & $0.606 I$ & 0.3870 & 0.3078 & 0.3233 & 2.5355 & 2.7277 & 2.7006 & $2.627 I$ & 2.3930 & 2.1747 & 2.1573 \\
\hline $0.6-0.7$ & 75 & 0.5427 & 0.6875 & 0.6554 & 0.5275 & 0.2775 & $0.158 \mid$ & 0.1735 & 2.3647 & 2.6006 & 2.5507 & 2.5213 & 2.2464 & 2.0449 & 2.0358 \\
\hline $0.7-0.8$ & 75 & 0.4860 & 0.5928 & $0.6|4|$ & 0.4816 & 0.2347 & 0.1488 & 0.1420 & 2.4629 & 2.6264 & 2.6304 & 2.6524 & 2.3606 & 2.2654 & 2.2521 \\
\hline $0.8-0.9$ & 71 & -0.1785 & -0.0774 & -0.0927 & -0.2190 & -0.4304 & $-0.508 \mathrm{I}$ & -0.5060 & 2.1505 & 2.2816 & 2.2448 & 2.3065 & 2.2067 & 2.1949 & 2.1919 \\
\hline $0.9-1.0$ & 70 & -0.5282 & -0.4384 & -0.4628 & -0.5476 & -0.7223 & -0.7870 & -0.7964 & 1.5769 & 1.5848 & 1.5216 & 1.6387 & 1.6902 & 1.8584 & 1.8596 \\
\hline All & 739 & 0.1954 & 0.2859 & 0.2785 & 0.1758 & -0.0054 & $-0.068 \mid$ & $-0.046 I$ & I.8864 & 1.9199 & I.8824 & 1.8717 & I.7254 & 1.6607 & 1.6368 \\
\hline
\end{tabular}

covariance structure increased the evaluation statistics of the mixed model. The variance function selected clearly homogenizes residuals variances (Figure $2 \mathrm{c}$ ). The different variables included in the variance function revealed that heterogeneous residual variance within and between-trees was present in the dataset (Table 3). This finding agrees with Trincado and Burkhart (2006) and Yang et al. (2009), who also specified the error distribution to allow for heterogeneous variance within and between trees of different sizes. The inclusion of a continuous autoregressive error structure further improved the fit. However, despite all parameters being significant, generally, the standard errors of parameters estimate increased in comparison to a model that considered uncorrelated errors (Table 4).

It seems that in the fitting process, the assumption of correlated errors may be relaxed without seriously compromising the predictive capability of the model, by the inclusion of random effects, and after accounting for heterogeneous residual variances (Kozak, 2004).

Random effects parameters can be predicted using upper stem diameter measurements allowing for a calibrate stem profile curves to individual trees. We evaluated six calibration scenarios based on measuring additional upper stem diameter on each tree at 2.3, 3.3, 4.3, 5.3, 6.3, and 3.3 and $6.3 \mathrm{~m}$ stem heights.

As reported by Calama and Montero (2006); the use of additional upper stem diameter measurements as additional predictors in stem taper or volume models has been a common practice in forestry. Measures of bias and RMSE were computed by relative height stem classes and used to compare the mean and calibrated response using one or two stem diameter measurements. The lower portion of the stem bole presented the lowest bias when one upper stem diameters at $6.3 \mathrm{~m}$ were used for calibration except for relative height between $0-10 \%$. The lowest RMSE values obtained when two upper diameters were used for calibration. These results generally agree with previously reported research (Trincado and Burkhart 2006, Sharma and Parton 2009). However, similar predictive capability was observed when only one stem diameter measurement at $6.3 \mathrm{~m}$ was used for calibration over a relative stem height of 0.4 . The predictive capability of model was not greatly decreased when only one stem measurement at $6.3 \mathrm{~m}$ was used for calibration (Figure 4). The calibration of taper equations using one or two upper bole diameter measurements may improve stand volume estimations (Calama and Montero, 2006). An important limitation when localizing stem curves by calibration is the necessity of accurate upper stem diameter measurements on standing trees. Kozak (1998) and Arias-Rodil et al. (2017) concluded that measurements errors affected precision and bias of a taper model that included upper stem measurements as explanatory variables. Due to advances in laser technology, more accurate and affordable measurements of upper stem diameters are possible.

\section{CONCLUSIONS}

A nonlinear mixed-effects taper equation was developed for natural brutian pine in Northern Mediterranean of Turkey using the Max and Burkhart (1976)'s segmented taper equation. Based on evaluation statistics, random effects were included $\beta_{1} \beta_{3}$ and $\beta_{4}$. With the inclusion of random-effects, residual variance and autocorrelation was not completely eliminated. Therefore, residual variance and autocorrelation were modelled by variance function and $\mathrm{CAR}(\mathrm{I})$ model and this mixedeffects model exhibited homogeneous residual variance for all relative stem heights. The mixed-effects model provided more precise upper stem diameter predictions than the fixed-effects model, especially for the lower portion of the stem bole; where the larger amount of stem 
volume is concentrated. The inclusion of random-effects parameters for a new tree based on upper stem diameter measurements increased the predictive capability of the model. A calibrated response using two stem diameter measurements was partly better than using only one stem diameter for brutian pine trees.

\section{ACKNOWLEDGEMENTS}

We would like to thank Dr. Guillermo Trincado from Universidad de Austral de Chile for his valuable help at the calibration process of the mixed-effects taper model.

\section{REFERENCES}

AKAIKE, H. A. new look at the statistical model identification. IEEE transactions on automatic control, v. 19, n. 6, p. 716-723, 1974.

ARIAS-RODIL, M.; DIÉGUEZ-ARANDA, U.; RODRÍGUEZ PUERTA, F;; LÓPEZ-SÁNCHEZ, C.A.; CANGA LÍBANO, E.; CÁMARA OBREGÓN, A. Modelling and localizing a stem taper function for Pinus radiata D. Don in Spain. Canadian Journal of Forest Research, v. 45 p. 647-658, 2015.

ARIAS-RODIL, M.; DIEGUEZ-ARANDA, U.; BURKHART, H. E. Effects of measurements error in total tree height and upper-stem diameter on stem volume prediction. Forest Science, v. 63, n. 3, p. 250-260, 2017.

BIGING, G. S. Taper equations for second-growth mixed conifers of Northern California. Forest Science, v. 30, (4), I I03-I| |7. 1984

BOZKURT, A. Y.; GOKER, Y. Forest products utilization. Istanbul University Press, Istanbul, 1996.

BROOKS, J. R.; JIANG, L.; OZÇELIK, R. Compatible stem volume and taper equations for Brutian pine, Cedar of Lebanon, and Cilicica fir in Turkey. Forest Ecology and Management, v. 256 n. I-2, p. |47-I5I, 2008.

BOYDAK, M. Silvicultural characteristics and natural regenaration of Pinus brutia Ten.- a review. Plant Ecology, v. I7I, p. I53-I63, 2004.

BURKHART, H. E.; WALTON, S. B. Incorporating crown ratio into taper equations for loblolly pine trees. Forest Science, v. 3I, n. 2, p. 478-484, 1985.

BURKHART, H. E.; TOMÉ, M. Modeling forest trees and stands. Springer Science \& Business Media, 2012.

CALAMA, R.; MONTERO, G. Stand and tree-level variability on stem form and tree volume in Pinus pinea L.: a multilevel random components approach. Forest Systems, v. I5, n. I, p. 24-4I, 2006.

CAO, Q.V.; BURKHART, H.E.; MAX, T.A. Evaluation of two methods for cubic-volume prediction of loblolly pine to any merchantable limit. Forest Science, v. 26, n. I, p. 7I-80, 1980.

CAO, Q. V.; WANG, J. Calibrating fixed-and mixed-effects taper equations. Forest Ecology and Management, v. 262, n. 4, p. 67I-673, 201 I.

CAO, Q. V.; WANG, J. Evaluation of methods for calibrating a tree taper equations. Forest Science, v. 6I, n. 2, p. 2I3-219, 2015.

CLARK III, A.C.; SOUTER, R.A.; SCHLAEGEL, B.E. Stem profile equations for southern tree species. USDA For. Serv. South. Res. Pap. SE-282. Asheville, NC, I99I.

COBLE, D. W.; HILPP, K. Compatible cubic-foot stem volume and upper-stem diameter equations for semi-intensive plantation grown loblolly pine trees in East Texas. Southern Journal of Applied Forestry, v. 30 n. 3, p. I32-14I, 2006.

DAVIDIAN, M.; GILTINAN, D. M. Nonlinear models for repeated measurement data. Chapman and Hall, London, UK, 1995.

DIEGUEZ-ARANDA, U.; CASTEDO-DORADO, F.; ALVAREZ, J.G.; ROJO, A. Compatible taper function for Scots pine plantations in northwestern Spain. Canadian Journal of Forest Research, v. 36, p. I I 90-1 205, 2006.

FANG, Z.; BORDERS, B. E.; BAILEY, R. L. Compatible volume taper models for loblolly and slash pine based on system with segmentedstem form factors. Forest Science, v. 46, p. I-12, 2000.

GDF. Forest Resources. The General Directorate of Forests, Ankara, 2006. 159p.

GOMEZ-GARCIA, E.; CRECENTE-CAMPO, F; DIEGUEZARANDA, U. Selection of mixed-effects parameters in a variable-exponent taper equation for birch trees in northwestern Spain. Annals of Forest Science, v. 70, p. 707-715, 2013

JIANG, L.; LIU, R. Segmented taper equations with crown ratio and stand density for Dahurian Larch (Larix gmelinii) in Northeastern China. Journal of Forestry Research, v. 22, p.347-352, 2011 .

KLOS, R.J.; WANG, G.G.; DANG, Q.L.; EAST, E.W. Taper equations for five major commercial tree species in Manitoba, Canada. Western Journal of Applied Forestry, v. 22, n. 3, p. 163-170, 2007.

KOZAK, A.; MUNRO, D.O.; SMITH, J.H.G. Taper functions and their application in forest inventory. Forest Chronicle v. 45, p. $278-283,1969$.

KOZAK, A. variable-exponent taper equation. Canadian Journal of Forest Research, v. I8, n. II, p. I363-I368, 1988.

KOZAK, A. Efects of upper stem measurements on the predictive ability of a variable-exponent taper equations. Canadian Journal of Forest Research, v. 28, n. 7, p. 1078-1083, 1998. 
KOZAK, A. My last words on taper equations. The Forestry Chronicle, v. 80, n. 4, p. 507-5I5, 2004.

LEITES, L. P.; ROBINSON, A. P. Improving taper equations of loblolly pine with crown dimensions in a mixed-effects modeling framework. Forest Science, v. 50, n. 2, p. 204212,2004

LI, R.; WEISKITTEL, A. Comparison of model forms for estimating stem taper and volume in the primary conifer species of the North American Acadian Region. Annals of Forest Science, v. 67, n. 3, p. 302, 2012.

LIU, Y.; TRANCOSO, R.; MA, Q.; YUE, C.; WEI, X.; BLANCO, J. A. Incorporating climate effects in Larix gmelinii improves stem taper models in the Greater Khingan Mountains of Inner Mongolia, northeast China. Forest Ecology and Management, v. 464, p. II8065, 2020.

MAX, T. A.; BURKHART, H. E. Segmented polynomia regression applied to taper equations. Forest Science, $v$. 22 , n. 3, p. 283-289, 1976

MUHAIRWE, C.K.; LEMAY, V.M.; KOZAK, A. Effects of adding tree, stand, and site variables to Kozak's variable -exponenttaper equation. Canadian Journal of Forest Research, v. 24, p. 252-259, 1994.

ORMEROD, D. W. A simple bole model. Forest Chronicle, v. 49 , p. 136-138, 1973.

PANCOAST, A. Evaluation of taper and volume estimation techniques for ponderosa pine in eastern Oregon and eastern Washington. 20I8. 50 p. MS Thesis. Oregon State University, Oregon, USA.

PINHEIRO, J. C.; BATES, D. M. Mixed-effects models in S and S-Plus. Springer, New York, 2000.

SABATIA, C. O.; BURKHART, H. E. On the use of upper stem diamaters to localize a segmented taper equation to new trees. Forest Science, v. 6I, n. 3, p. 4II-423, 20 I 5.

SAKICI, O. E.; MISIR, N.; YAVUZ, H.; MISIR, M. Stem taper functions for Abies nordmanniana subsp. bornmulleriana in Turkey. Scandinavian Journal of Forest Research, v. 23 , n. 6, p. 522-533, 2008.
SAKICI, O. E.; OZDEMIR, G. Stem taper estimations with artificial neural networks for mixed Oriental beech and Kazdaği fir stands in Karabük region, Turkey. CERNE, 24, P. 439-45I, 2018.

SAS INSTITUTE INC. SAS/STAT User's Guide, Version 9.3, SAS Institute Inc., Cary, NC, $201 \mathrm{I}$.

SHARMA, M.; ZHANG, S. Y. Variable-exponent taper equations for jack pine, black spruce, and balsam fir in eastern Canada. Forest ecology and management, v. 198, n. I-3, p. 39-53, 2004

SHARMA, M.; PARTON, J. Modeling stand density effects on taper for jack pine and black spruce plantations using dimensional analysis. Forest Science, v. 55, n. 3, p. 268-282, 2009.

TASISSA, G.; BURKHART, H. E. An apllication of mixed effects analysis to modeling thinning effects on stem profile loblolly pine. Forest Ecology and Management, v. I03, n. I, p. 87-101, 1998.

TRINCADO, G.; BURKHART, H. E. A generalized approach for modeling and localizing stem profile curves. Forest Science, v. 52, n. 6, p. 670-682, 2006

VALENTI, M. A.; CAO, Q. V. Use of crown ratio to improve loblolly pine taper equations. Canadian Journal of Forest Research, v. 16, n.50, p. I|4|-||45, 1986.

XU, W. Modeling jack pine (Pinus banksiana Lamb) and black spruce (Picea mariana (mill.) BSP) growth and yild in Manitoba. PhD Thesis, The University of Manitoba, 2012.

YANG, Y.; HUANG, S.; TRINCADO, G.; MENG, S. X. Nonlinear mixed-effects modeling of variable-exponent taper equations for lodgepole pine in Alberta, Canada. European Journal of Forest Research, v. I28, n. 4, p. 4I5-429, 2009. 